\title{
Carbon Fiber Reinforced Polymers (CFRP) Technique and Its Application in Bridge Engineering in The Future
}

\author{
Hua Yin Sun ${ }^{\mathrm{a}}$, Ya Li Liu ${ }^{\mathrm{b}}$ and Wei Li Zhou ${ }^{\mathrm{c}}$ \\ Yangtze Normal University, Fuling District, Chongqing, China \\ asunhuayin123@163.com, blyllary@163.com, 'chouweili117@163.com
}

\begin{abstract}
Keywords: Bridge reinforcement; Carbon fiber; Prestressed carbon fiber; Fire proof carbon fiber; Carbon fiber with memory
\end{abstract}

\begin{abstract}
Based on the overview of traditional bridge reinforcement method, this article derives the shortage of the traditional strengthening methods and reinforcement of the common problem, in which educes the characteristics, properties and advantages of carbon fiber reinforced polymers(CFRP) and strengthening methods, then makes a further outlook for the application of CFRP in bridge reinforcement, which leads to the development of new materials and CFRP in other engineering fields, such as the prestressed carbon fiber reinforcement, fire proof carbon fiber, and carbon fiber composites with memory, etc.
\end{abstract}

\section{Introduction}

With the rapid development of highway in our country, bridge is increasingly becoming an important part of the big transportation industry in China. But when a bridge is built and run after a period of time, inevitably corresponding diseases occurs. Because the problematic Bridges do not allow to be torn down in most cases, the reinforcement and maintenance will become an eternal topic in the development of bridges. Witthe rapid developme nt of bridge reinforcement and maintenance technology, CFRP, with their incomparable advantages, gradually replace other ways to become the mainstream of reinforcement and maintenance technology. [1, 2]

\section{The Commonly Traditional Strengthening Methods of Bridge}

It is necessary to introduce the traditional bridge reinforcement methods for comparison before the introduction of CFRP. The traditional strengthening methods commonly used mainly are as follows: Reinforcement Method of Enlarging Section. Adding reinforced for the original component and simultaneously pouring concrete member in the outside to increase the section size, reinforcement method of enlarging the section can achieve the purpose of improving the bearing capacity of cross section. Enlarging section method is a traditional method used for a long time. But it is also a very effective method. It can not only improve flexural, compressive and shear capacity of the component, at the same time it can also be used to repair concrete section which has been damaged, and to increase its durability, so this method is very widely used. It also has some disadvantages contain the long construction period, increasing weight of the bridge, the big occupied space, and huge impact on the environment, etc. [3]

Enclosing Steel Reinforcement. Enclosing steel reinforcement reinforced steel-encased of concrete component by using latex cement, epoxy resin grouting, etc. The mainly mechanism of this method is improving the bearing capacity and deformation capacity of concrete by constraining the original component to improve the bearing capacity and deformation capacity of concrete. Similar to the steel tube of concrete filled steel tube, Steel encased here plays a role of ferrule [4, 5]. Enclosing steel reinforcement can greatly improve the flexural and compressive properties of the component. As a result of steel material, relatively short construction period, and the relatively small space, this method is widely used in the axial compression member and small eccentric compression member in which the dimensions are not allowed to increase, and need to greatly improve the bearing capacity. 
Prestressing Strengthening Method. Prestressing strengthening method is a method to improve the bearing capacity of components through the prestressed reinforced the component prestressing to shoulder some of the load. It generally used in external prestressing reinforcement. Prestressed bar reinforcement is widely applied to the bending and tensile components for the beam or slab bridges. It not only improves the bearing capacity, but also improves cross section stiffness and reduces the crack width and deflection at the same time. In addition, it is very effective for improving the crack resistance of component after reinforcement. Furthermore, it also has the characteristicswhich takes up the little space and short construction period, etc. But because of involving the prestressed tension control,it has a high requirement of construction technology and big construction difficulty, in addition, there are still some problems such as lateral stability.

Bonding Steel Plate Strengthening Bonding steel plate strengthening is a reinforcement method which using special cement bonding steel plate in the bridge or slab floor. It can effectively improve the bearing capacity and deformation ability of structure. It also has the characteristics of convenient construction, short construction period, small footprint, low impact on the environment, etc. With the advent of JGN building structural adhesive, there have been great leap forward in bonding steel plate method, it has started to be used in a lot of practical engineering.

Shotcrete Technique. Shotcrete technique is a reinforcement technology which sprays the good concrete on the spray surface at high speed through injection machinery, to condense sclerosis, and reach the purpose of strengthening. After practical test, it has been confirmed that sprayed concrete has good mechanical properties and good durability. Especially it has good adhesive strength with concrete, masonry and other building materials, and good for the tensile stress and shear stress pass on the surface of the combination.

\section{Fiber Reinforced Plastics (FRP) Method}

The Introduction and Performance of FRP Materials. The reinforcement methods mentioned above are all the early and mature traditional strengthening methods. They have some shortcomings more or less. This requires that reinforcement and maintenance of the bridge will develop in the direction of overcoming these weaknesses. To solve the problem above, since the $1980 \mathrm{~s}$, foreign countries began the application of FRP in the concrete. [6, 7]

FRP generated by micro fiber which parceled in resin matrix. Fiber has the effect of stiffening enhancement, while resin has the effect of bonding fiber, to achieve the purpose of reinforcement through the pass of the shearing force between the resin fiber cloth and concrete by resin. Because of lightweight, high strength, corrosion resistance, fatigue resistance and other properties, FRP gradually has been widely used in bridge reinforcement including glass fiber reinforced plastics (GFRP) and carbon fiber reinforced polymers (CFRP) and aramid fiber reinforced polymers (AFRP). [8,9] their various mechanical properties are given as follows:

Table 1 Main mechanical properties of FRP

\begin{tabular}{|c|c|c|c|c|c|}
\hline \multicolumn{2}{|r|}{ fiber types } & $\begin{array}{l}\text { elastic modulus } \\
\text { [GPA] }\end{array}$ & $\begin{array}{c}\text { tensile strength } \\
{[\mathrm{MPA}]}\end{array}$ & $\begin{array}{l}\text { ultimate tensile } \\
\text { strain }[\%]\end{array}$ & $\begin{array}{c}\text { density } \\
{\left[\mathrm{G} / \mathrm{CM}^{3}\right]}\end{array}$ \\
\hline \multirow{5}{*}{ CFRP } & common & $220-235$ & $2050-3790$ & 1.2 & \multirow{5}{*}{$1.5-1.6$} \\
\hline & high strength & $220-235$ & $3790-4825$ & 1.4 & \\
\hline & extra-high strength & $220-235$ & $4825-6200$ & 1.5 & \\
\hline & high elastic modulus & $345-515$ & $1725-3100$ & 0.5 & \\
\hline & extra-high elastic modulus & $515-690$ & $1375-2400$ & 0.2 & \\
\hline \multirow{2}{*}{ GFRP } & E-Glass & $69-72$ & $1860-2685$ & 4.5 & \multirow{2}{*}{$1.2-2.1$} \\
\hline & S-Glass & $86-90$ & $3445-4135$ & 5.4 & \\
\hline \multirow{2}{*}{ AFRP } & common & $69-83$ & $3445-4135$ & 2.5 & \multirow{2}{*}{$1.2-1.5$} \\
\hline & high performance & $110-124$ & $3445-4135$ & 1.6 & \\
\hline & steel bar & $200-210$ & $300-400$ & & 7.9 \\
\hline
\end{tabular}


By comparison, CFRP has relatively best comprehensive properties of the three kinds of materials. Japan is one of the earliest countries which strengthened bridge engineering with CFRP clothand pasted and reinforced concrete box girder of the east of highway viaduct used CFRP cloth both inside and outside in 1994; After Kobe earthquake in 1995, CFRP cloth has been fully applied, a lot of bridge piers were wrapped and reinforced by CFRP cloth, and the strength and stress state of the bridge piers are obviously improved and strengthened.

The research still relatively lags behind In China, but it still caused attention in many research institutions in recent years. [10]

FRP Construction Method of External Supplement and Strong Technology. FRP construction methods of external supplement and the strong technology mainly can be divided into four kinds: dry system, wet system, pre extracting system and processing system.

Dry system: It is a way in which directly pasting unidirectional and multidirectional fiber cloth on the concrete surface with good colloid in the construction site.

Wet system: It is a way that unidirectional and multidirectional fiber cloth diping with colloid first in the construction site, and bonding to concrete surface after.

Putting dry and wet systems construction is more flexible, but it should guarantee the smooth of fiber cloth, full resin impregnation and the ventilation of the environment while construction.

Pre extracting system: Pre extracting system refers to a construction method that unidirectional and multidirectional fiber cloth will be pasted to the reinforcing component after impregnated resin in factory.

Pre-processing system: Pre-processing system is the commonly used way for the gummed fiberboard or fiber shell. Comparing with the former several systems, the pretreatment system does not apply to reinforcement of irregular component.

Here is a piece of renderings about CFRP reinforcement:
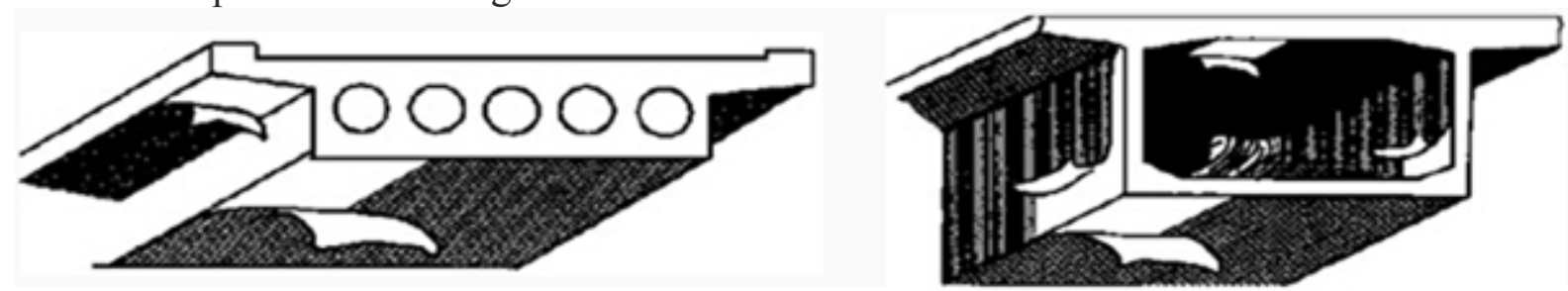

Figure. 1 Diagram about CFRP reinforcement for concrete beam

The Advantages and Shortcomings of CFRP Strengthening Method. [11] The advantages: 1) Not increase the dead load and section size; 2) As the material is very thin, so it will not reduce the headroom under bridge; 3) The construction is convenient, especially the inside of the box girder homework space is limit, and its operability is very good; 4) It can be adapted to different shape of component, and convenient for forming; 5) By effectively bonding the material of the epoxy resin series and structure, it does not need to set the anchor bolts, etc., and has no new injury on the original structure; 6) It can be pasted several layers according to the stress; 7) As a kind of composite material, it has excellent resistance to chemical corrosion; 8) Fatigue property is good.

The shortcomings: 1) Although the CFRP materials have good tensile strength, but its compressive strength is not optimistic; 2) Due to the abilityof resin for transporting shear is limited, it will cause insufficient stiffness; 3) The fire resistance is poorer, and it may fail at any time when it catches a fire; 4) The ductility is poor and internal force distribution is not uniform.

\section{Some Prospects on theU se of CFRP Material in Actual Engineering}

The Problem which Needs Further Development. With the localization process of the FRP and advances of the materials technology, FRP will undoubtedly bring considerable economic benefit and social benefit. To better solve the deficiency of FRP materials in practical use, some further research below must be done: 
First, in order to solve disadvantages of low fire proofing of FRP materials, we can try to develop FRP material with good fire proofing, reinforce the fire proofing while reinforcing the bridge used FRP. Second, we will not necessarily limit the fiber reinforcing materials to solid. We should also develop in the liquid. This not only can cooperate with built-in hollow capsule in Japan and with a built-in intelligent self-healing concrete hollow tubein the United States (Fig. 2), become a capsule or the fluid repaired in the tube, it can also be used for direct injection and perfusion reinforcement after cracking. Third, we can take the lead in planting bar in the bottom of the beam cracking test, and consider memory alloy implant, and then paste CFRP cloth. This is similar to the steel pipe and concrete in concrete filled steel tubular members, which can make memory alloy and CFRP cloth play to their advantages, getting a better reinforcement.Forth, the study of strengthening method used prestressed FRP is very important, W.W. Wang at southeast university does a lot of research in this aspect, Fig. 3 below are the post-tensioned method of CFRP reinforced beam layout. Fifth, by optimizing the FRP composite material, and using the structure materials in different stages of fracture characteristics of fiber materials and different electrical conductivity, and configuration of advanced self-induction and measurement system, the development of self-diagnosis intelligent fiber and intelligent structure is significant [12].

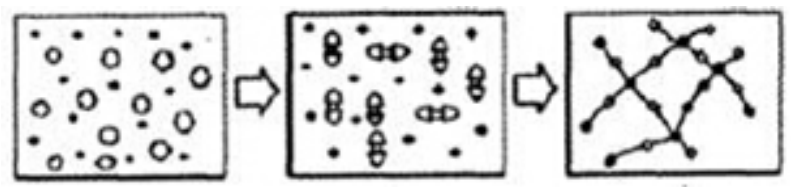

(a)

(b)

(c)

healing pipeline of glass fiber

Mechanism schematic diagram of built-in capsule which

is bionicand self-healing

a) Capsules which contains repair agent had been buried in the concrete; b) After present of the cracks, the capsul $\epsilon$ ruptured and repair agent flowed out; c) The repair agent of outflow repaired the cracks

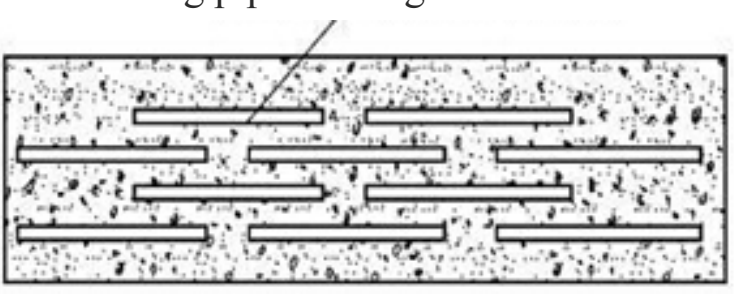

Figure 2. Smart concrete with internal hollow capsules and glass fiber tubes

The Prospect of FRP Technology Used in Other Ways. First, structure antisepsis problem has always been one of the most prominent problems in all infrastructure of sea. Currently concrete structures in Marine reinforced under construction, use the thickness of concrete cover and corrosion protection measures, its internal steel chlorine salt corrosion prevention is only 15 years or so, it is far apart with the permanent or semi-permanent Marine structure durable requirements. Using FRP concrete or FRP concrete composite structure can fundamentally solve the problem of rebar (steel) corrosion in Marine engineering, its significance is self-evident [13]. Next, under alpine environment, infrastructure construction and maintenance is expensive, construction cycle is too long. Therefore, it is one of the major technical problems to improve the construction quality and reduce maintenance cost for various infrastructure projects to build or planned. Replace rebar with FRP tendons, and make concrete structure of composite material of free maintenance, so as to achieve the purpose of improving infrastructure durability and prolonging life.

\section{Summary}

A large number of engineering practices have proved that the use of FRP for structural reinforcement technology development provides a qualitative leap. It can not only eliminate the disadvantages of traditional strengthening methods, but also has the advantages of high construction quality, high construction efficiency, good reinforcement effect and good comprehensive benefits, etc. With the deepening of the research, people keep informed of its nature, coupled with the application in intelligent bridge development, there is no doubt that the carbon fiber composite materials will lead to a new revolution in the innovate field and civil engineering reinforced 


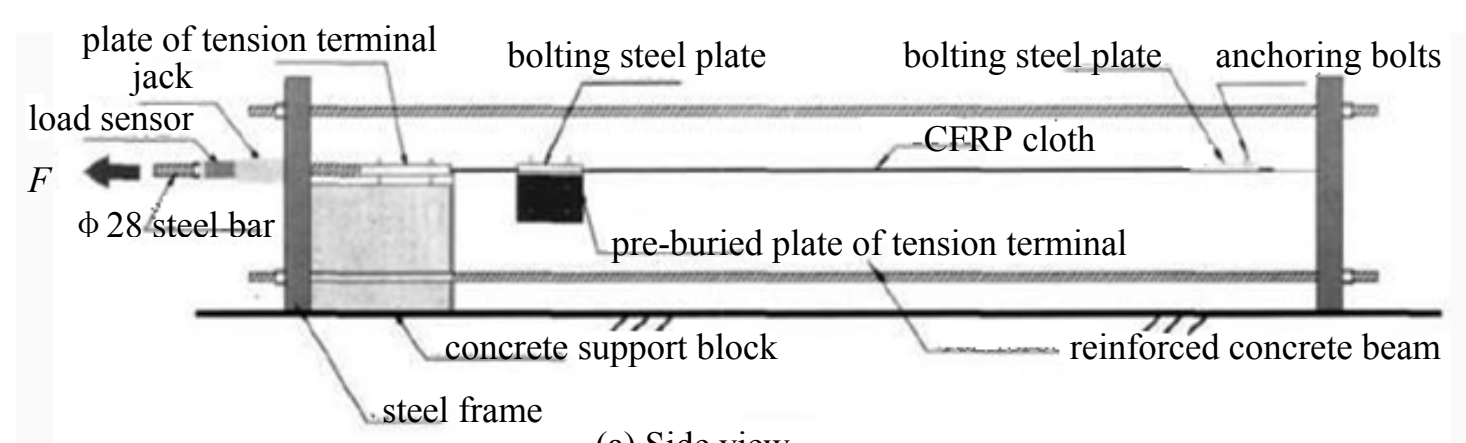

(a) Side view

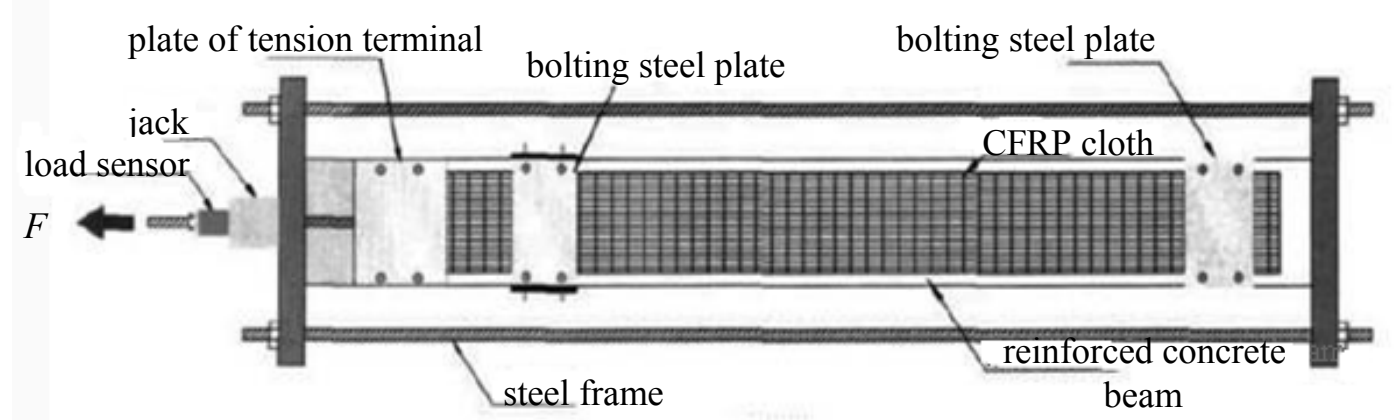

(b) Top view

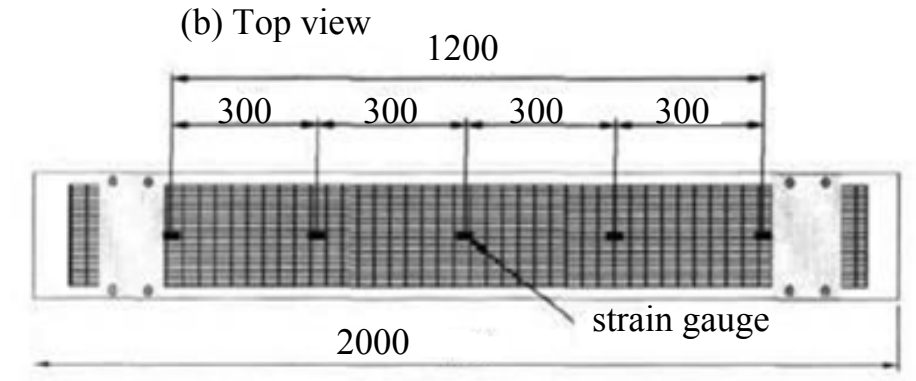

(c) Layout of strain gauge

Fig. 3 Post-tensioned method of CFRP reinforced beam lavout

\section{References}

[1] J. Li: Shanxi Architecture, Vol. 39 (2013) No.3, p.109. (In Chinese)

[2] Y.C. Zhang, D.X Xu: Journal of Chongqing Jiaotong University, Vol. 6 (2010) No.22, p.41. (In Chinese)

[3] W.W. Wang, G.F. Zhao: Technology and Application of FRP Reinforced Concrete (China Construction Industry Press, China 2003).

[4] R.Y. Lin: Guangdong Construction Materials, No.6 (2013), p.28. (In Chinese)

[5] Y.T. Wang: Science \& Technology Information, No.21 (2009), p.674. (In Chinese)

[6] W.C. Xue, Y. Tan: Glass Fiber Reinforced Plastics Composite Materials, No.5 (2007), p.53. (In Chinese)

[7] X.J. Chen, Y.D. Fu: Bridge Construction, Vol. 5 (2011) No.3, p.10. (In Chinese)

[8] D. Chen, C.H. Jiang, W. Zhang, and Y.D. Liao: Journal of Hohai University (Natural Sciences), Vol. 35 (2007) No.5, p.534. (In Chinese)

[9] L.J. Zhou, J.N. Zhu: Guangdong Construction Materials, Vol. 10 (2010) No.22, p.88. (In Chinese)

[10]Y.L. Zheng: Fujian Construction Materials, No.7, p.19. (In Chinese) 
[11]M.Y. Liu, K.B. Li, and K.L. Chen: Journal of Heilongiiang Institute of Engineering, Vol. 16 (2012) No.4, p.36. (In Chinese)

[12] K.Y. C.S. Shi, and N.Q. Zhao: Sciencepaper Online, Vol. 3 (2008) No.4, p.250. (In Chinese)

[13]Q.F. Wang, Y.X. Yang and Q.R. Yue: Journal of Huaqiao University (Natural Science), Vol. 26 (2005) No.1, p.1. (In Chinese) 